\title{
EEG beta-power changes reflect motor involvement in abstract action
}

\section{language processing

\author{
Franziska Schaller*, Sabine Weiss, Horst M. Müller
}

Experimental Neurolinguistics Group, Bielefeld University, Universitaetsstrasse 25, 33615 Bielefeld, Germany

Cluster of Excellence "Cognitive Interaction Technology" (CITEC), Inspiration 1, 33619 Bielefeld, Germany

\section{A R T I C L E I N F O}

\section{Article history:}

Received 15 September 2016

Revised 20 December 2016

Accepted 26 January 2017

\section{Keywords:}

Embodiment

Abstract language

Action verbs

Beta-oscillation

Event-related desynchronization (ERD)

\begin{abstract}
A B S T R A C T
Brain oscillations in the $\alpha$ - and $\beta$-range become suppressed during motor processing and motor imagery. It has recently been discussed that such power changes also occur during action language processing. In our study, we compared $\beta_{2}$-oscillations $(16-25 \mathrm{~Hz}$ ) during the observation of prototypical arm movements (revealed via motion tracking) as well as during semantic processing of concrete and abstract sentences containing arm-related action verbs. Whereas we did find a strong desynchronization in the $\beta_{2}$-range during action observation, the processing of action sentences evoked a rather weak desynchronization. However, this desynchronization occurred for action verbs in both concrete and abstract contexts. These results might indicate a tendency for abstract action language to be processed similar to concrete action language rather than abstract sentences. The oscillation patterns reflect the close relationship between language comprehension and motor functions - one of the core claims of current theories on embodied cognition.
\end{abstract}

(c) 2017 Elsevier Inc. All rights reserved.

\section{Introduction}

Brain oscillations in the $\mu$ - and $\beta$-range of the human EEG are strongly related to sensorimotor processes and sometimes regarded as idling rhythms that are apparent as long as the sensorimotor system is in a resting state (Baker, 2007; Kuhlmann, 1978). Whereas oscillations in the $\mu$-range are considered to originate in the somatosensory system, the $\beta$-rhythm might rather be linked to the motor system (Pfurtscheller \& Neuper, 1997; Ritter, Moosmann, \& Villringer, 2009). However, it has been observed that $\mu$-oscillations become suppressed during action execution, action observation, and even during motor imagery (McFarland, Miner, Vaughan, \& Wolpaw, 2000; Pfurtscheller, Brunner, Schlögl, \& Lopes da Silva, 2006). Pfurtscheller, Stancák, and Neuper (1996) and Pfurtscheller and Lopes da Silva (1999) gave a detailed description of event-related $\mu$ - and $\beta$-rhythm synchronization (ERS) and desynchronization (ERD) processes in relation to voluntary hand/ wrist movements. An ERS is defined as an increase of amplitude after the onset of a certain stimulus, which goes back on numerous neurons firing at the same time. In contrast, in case of an ERD, the synchrony of the respective neuronal assemblies decreases, which

\footnotetext{
* Corresponding author at: Experimental Neurolinguistics Group, Bielefeld University, Universitaetsstrasse 25, 33615 Bielefeld, Germany.

E-mail addresses: franziska.schaller@uni-bielefeld.de (F. Schaller), sabine. weiss@uni-bielefeld.de (S. Weiss), horst.mueller@uni-bielefeld.de (H.M. Müller).
}

in turn causes a decrease of amplitude (Pfurtscheller \& Lopes da Silva, 1999). For self-paced finger movements, Pfurtscheller et al. (1996) reported $\mu$ - and $\beta$-rhythm desynchronization in the Rolandic region contralateral to the hemisphere processing action execution, which started $2 \mathrm{~s}$ before movement onset. Immediately before the movement, this desynchronization became symmetrical bilaterally. During the movement, a bilateral ERD was reported. Whereas the recovery of the $\mu$-rhythm took about 2-3 s after movement offset, $\beta$-oscillations $(16-20 \mathrm{~Hz})$ showed a rather quick recovery to the baseline within $1 \mathrm{~s}$ after movement offset. Additionally, the $\beta$-range showed a short contralateral postmovement ERS ( $\beta$-rebound) (Pfurtscheller et al., 1996). Hari et al. (1998) analyzed the neuromagnetic $\beta$-rebound in precentral motor cortex in a frequency range between 15 and $25 \mathrm{~Hz}$ while participants manipulated an object and while they were observing someone else manipulating the object. They additionally stimulated the median nerves in both arms. Compared to a neutral baseline condition, in which the nerves were stimulated during rest, the $\beta$-rebound disappeared when participants manipulated the object and got strongly reduced when they observed action execution (Hari et al., 1998). In an MEG study with a similar design, Järveläinen, Schürmann, and Hari (2004) analyzed the poststimulus rebound during goal-directed and non-goal-directed chop-stick use observation. In addition to a stronger suppression of the rebound during goal-directed tool manipulation, the difference to 
the rebound related to non-goal-directed manipulation was correlated with the participants' experience in chop-stick usage. Beside their relevance for the mirror neuron system, these findings indicated an experience-based responsiveness of motor-related brain oscillations (Järveläinen et al., 2004). Hari et al. (2014) further observed that two different neural processes might occur during action observation: one which depicts itself as a decrease of MEG power between 7 and $15 \mathrm{~Hz}$ and is considered to reflect mirroring activity, and another, showing an increase in cortex - muscle coherence around $18 \mathrm{~Hz}$, which might suppress action imitation.

Beside their sensitivity towards voluntary movements, $\beta$-power changes are related to various aspects of language processing (for a detailed discussion see Weiss \& Müller, 2012a). They are responsive to both syntactic and semantic violations (Bastiaansen, Magyari, \& Hagoort, 2010; Davidson \& Indefrey, 2007; Luo, Zhang, Feng, \& Zhou, 2010; Weiss \& Müller, 2003), reflect binding processes at the word and sentence level (von Stein, Rappelsberger, Sarnthein, \& Petsche, 1999; Weiss \& Rappelsberger, 1996; Weiss et al., 2005), and are related to verbal memory processes (Bastiaansen et al., 2010; Weiss \& Rappelsberger, 2000). Further, $\beta$-oscillations are very sensitive towards dissociation between concrete and abstract concepts (Weiss \& Müller, 2013; Weiss \& Rappelsberger, 1996, 1998). Recently, in the context of the embodied language theory, studies revealed that power decreases in the $\beta$ - as well as the $\mu$-band are correlated with the processing of concrete action related language (Alemanno et al., 2012; Fargier et al., 2012; Moreno, de Vega, \& León, 2013; Moreno et al., 2015; van Elk, van Schie, Zwaan, \& Bekkering, 2010). This finding strongly sup-ports the theory of embodiment, which, in the case of language processing, indicates that understanding linguistic input requires a mental neural simulation of respective sensorimotor information in somatosensory and motor areas (Barsalou, 1999, 2008; Gallese \& Lakoff, 2005; Glenberg \& Kaschak, 2003; for a review see also Buccino, Colagè, Gobbi, \& Bonaccorso, 2016). For instance, Gallese and Lakoff (2005) suggested that the neural substrates underlying the processing of perceptive input, action execution, action simulation, action imagery and linguistic comprehension are equal and that all of these processes require the activation of sensorimotor circuits. These assumptions are supported by the results of several fMRI and TMS studies revealing an activation of primary and secondary motor areas during the processing of action verbs (Boulenger, Hauk, \& Pulvermuller, 2009; Desai, Binder, Conant, \& Seidenberg, 2010; Hauk, Johnsrude, \& Pulvermüller, 2004; Tomasino, Fink, Sparing, Dafotakis, \& Weiss, 2008). Fischer and Zwaan (2008) summarized the role of sensorimotor information for language processing as not being demonstrably necessary for language comprehension but as allowing for an enhanced understanding of linguistic input.

To compare the processing of action verbs in a human versus an animal context, van Elk et al. (2010) conducted an EEG experiment, in which they presented sentences containing concrete noun-verb pairs to participants (e.g., The athlete jumps over the hurdle. vs. The deer jumps over the fence.). Their claim was that motor imagery would be manipulated due to the difference in familiarity between human and animal actions. Beside an early ERD in the $\mu$-range (10$14 \mathrm{~Hz}$ ), they observed a desynchronization in the $\beta$-band (20-30 $\mathrm{Hz}$ ), which occurred in central electrode regions, specifically over left premotor areas, between 500 and 600 ms post verb onset. Due to the latencies of the effects, the authors concluded that the motor activity reflected by $\mu$ - and $\beta$-suppression corresponded to the retrieval of lexical-semantic information (van Elk et al., 2010). Moreno et al. (2013) observed both $\mu$ - (8-13 Hz) and $\beta$-ERDs (15$20 \mathrm{~Hz}$ ) in fronto-central electrodes over the sensorimotor cortex during action language processing. They compared power changes during the presentation of action and abstract sentences and during manual action observation. The presentation of action related stimuli (both verbal and visual) induced significant power suppression in comparison to abstract language stimuli. In a second study by Moreno et al. (2015), n o $\beta$-related $(13-20 \mathrm{~Hz}$ ) language effect could be observed, whereas $\mu$-power $(6-13 \mathrm{~Hz})$ got reduced during action sentence comprehension. However, the $\beta$ range chosen in the second study differed from the range analyzed in the first study and comprised both $\beta_{1}$ - and $\beta_{2}$-frequencies. Action related effects in the $\beta$-band seem to occur in higher $\beta$-frequencies, though (Pfurtscheller et al., 1996; van Elk et al., 2010). In sum, a suppression or desynchronization of $\beta$-oscillations related to action verb processing seems to occur later than comparable $\mu$-effects and seems not be detectable over both $\beta_{1}$ - and $\beta_{2}$-frequencies. Fig. 1 gives an overview of $\mu$ - and $\beta$-oscillations in response to action, language, and action language stimuli.

These electrophysiological studies suggested that an activation of sensorimotor areas is connected to concrete action language processing. A great number of behavioral and fMRI studies further supported this assumption (D'Ausilio et al., 2009; Glenberg et al., 2010; Hauk et al., 2004; Klatzky, Pellegrino, McCloskey, \& Doherty, 1989; Moseley \& Pulvermüller, 2014; Pulvermüller, Shtyrov, \& Ilmoniemi, 2005) and partly revealed that processing abstract action language (e.g., pushing the argument) leads to an activation of motor areas as well (Desai, Binder, Conant, Mano, \& Seidenberg, 2011; Desai, Conant, Binder, Park, \& Seidenberg, 2013; Glenberg et al., 2008; Romero Lauro, Mattavelli, Papagno, \& Tettamanti, 2013; Schaller, Weiss, \& Müller, in press; Wilson \& Gibbs, 2007). However, the effects following abstract action language seem to be weaker than those following concrete action language. Schaller et al. (in press) described a stronger motor priming effect on concrete than on abstract action language stimuli. Participants conducted a sensibility judgment on concrete and abstract sentences containing action verbs after the execution of a movement, which was either prototypical or unrelated with respect to the action verb in the sentence. Response times showed that in comparison to an unprimed condition, the comprehension of concrete action sentences was facilitated after the execution of a prototypical movement only. In contrast, comprehension of the abstract action sentences was facilitated by both prototypical and unrelated movements. This effect showed that there are differences between concrete and abstract action language processing with regard to the degree of the involvement of retrieved motor representations (Schaller et al., in press).

In the current study, we focused on $\beta$-oscillations and their responsiveness to abstract action language stimuli against the background of the embodied language theory. If motor representations should be involved in abstract action language processing, action related $\beta_{2}$-oscillations might show a desynchronization during the presentation of respective stimuli. With regard to the differences concerning concrete and abstract action language processing described by Schaller et al. (in press) we asked the following questions: Do brain oscillations, which are known to be responsive to action stimuli, differ during the comprehension of action verbs in concrete vs. abstract contexts? And are these brain responses comparable to those during action observation? The second question aimed at getting a better idea of whether the degree to which motor representations are activated during action observation is comparable to that during action language processing. To answer these questions, we investigated whether $\beta_{2}$-oscillations (16-25 Hz) during the observation of an arm-/hand-related movement would be similar to $\beta_{2}$-behavior during the processing of action verbs embedded in concrete and abstract sentences. As mentioned before, brain oscillations in the $\beta$-range are both related to motor processes and various aspects of language processing including the dissociation between concrete and abstract concepts. Thus, $\beta$-range behavior is highly relevant in the current study 


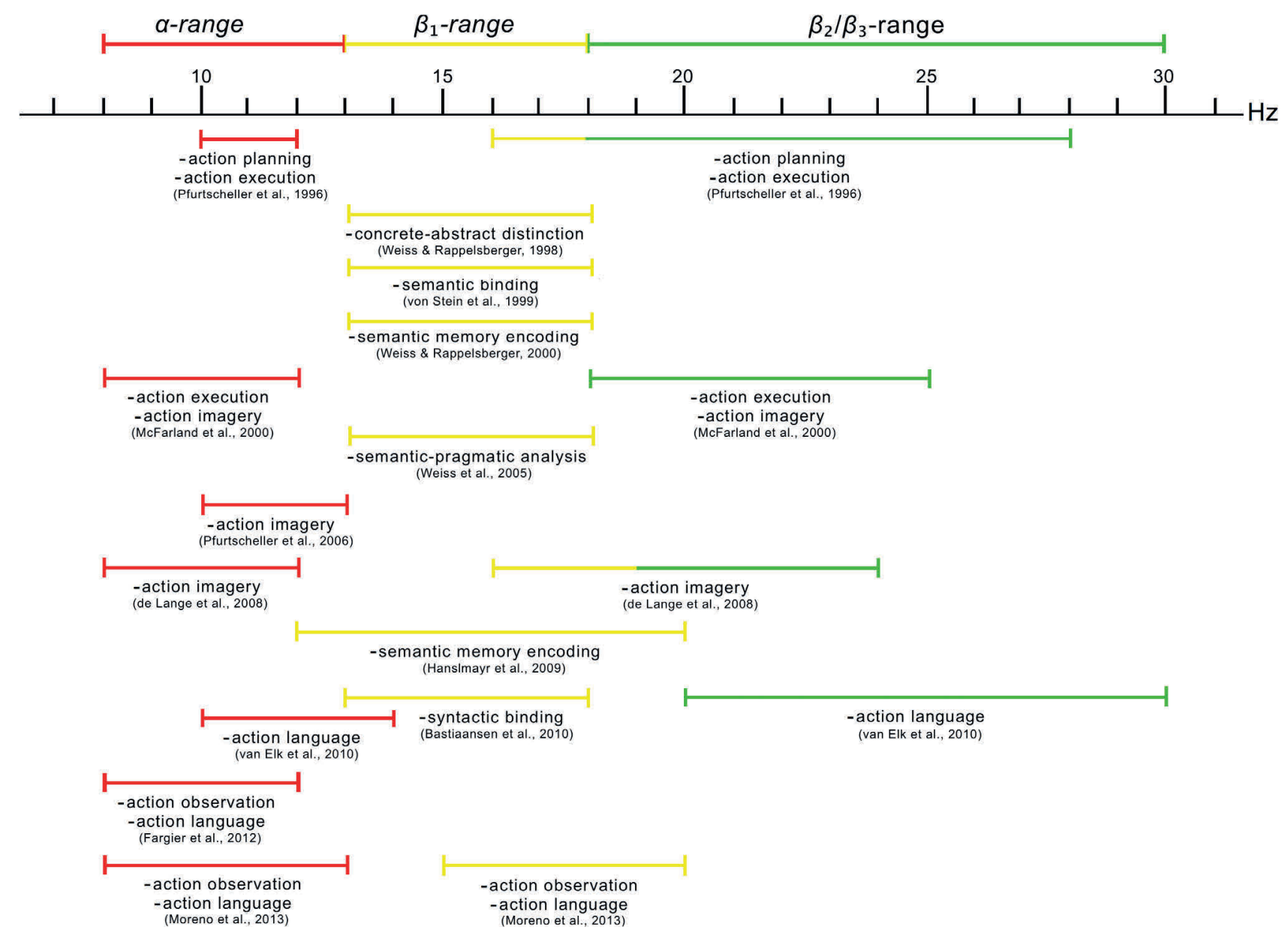

Fig. 1. Review of results concerning $\mu$ - and $\beta$-oscillations in response to action, language, and action language stimuli. Studies are shown in chronological order. Frequency ranges refer to Herrmann, Fichte, and Kubicki (1980).

looking at both action language and the contrast between action verbs in concrete and abstract contexts. In short video clips, we presented prototypical movements for action verbs and compared respective desynchronization patterns to those during the presentation of no-movement videos. In a second block, we aurally presented sentence stimuli that contained the corresponding action verbs in either a concrete or an abstract context and compared those to non-action abstract sentences. We expected $\beta$-oscillations to become suppressed during action observation, which should result in an ERD relative to the still video condition. We further expected desynchronization effects after the onset of action-related sentence final verbs but not after abstract control verbs.

\section{Material and methods}

\subsection{Participants}

30 monolingual German students (15 female) of Bielefeld University aged $20-31$ years $(M=24.6, S D=2.8)$ participated in the EEG study. Written informed consent was obtained from participants for publication of this study. All were right-handed with a mean lateralization quotient of $87.9(S D=12.3)$ according to a modified version of the Edinburgh Handedness Inventory (Oldfield, 1971). Four subjects were rejected before the analysis because of beta-blocker or anticonvulsant medication respectively. All remaining subjects declared that they did not suffer from auditory or motor diseases or restrictions that might have influenced their capability to fulfill the task and had not been under strong medication during two weeks prior to the experiment. Subjects were paid for their participation.

\subsection{Stimuli and design}

Two sets of stimuli were used in the EEG study. One set contained sentence stimuli, the other contained video material. The most important information concerning the stimuli is given below. Further details are provided in Schaller et al. (in press).

\subsubsection{Sentences}

197 German sentences were used as verbal stimuli. They were recorded with a semi-professional speaker in a sound studio. There were 50 semantically incongruous fillers and 147 critical sentences in the experiment. The critical stimuli were set up as triplets, comprising a concrete action sentence (e.g., "Ich habe die Handbremse gezogen." - I have pulled the hand break.), an abstract action sentence (e.g., "Ich habe die Konsequenz gezogen." - I have drawn the consequence.), and an abstract control sentence (e.g., "Ich habe die Konsequenz gefordert." - I have demanded the consequence.). Sentence structure was the same for every item with the target verb positioned at the end. Mean durations were $1595.5 \mathrm{~ms}$ $(S D=207 \mathrm{~ms})$ for sentences and $734.9 \mathrm{~ms}(S D=129.2 \mathrm{~ms})$ for verbs. The sentences in each triplet were matched according to gender of nouns, number of noun syllables and number of verb ; syllables. The sentences in each category were matched according 
to word frequency of nouns and verbs and co-occurrence of nouns with verbs. Matching stimuli according to these psycholinguistic criteria left us with only a limited pool of stimuli to draw from. The cloze-probability of the chosen items was evaluated and revealed a significant difference between the action stimuli (concrete and abstract) and the abstract control stimuli, with the cloze-probability of noun-verb pairs in the control sentences being significantly lower than in the action sentences. The two types of action sentences did not differ from each other. Due to the limited amount of possible stimuli, we decided to conduct the experiment despite the differences in cloze-probability. A possible influence on the current data is discussed in Section 4 below.

\subsubsection{Videos}

In total, we presented 58 videos. 29 videos showed an anonymized male model performing non-object-related movements that were prototypical for the action verbs, which were embedded in the sentence stimuli. The other 29 videos were used as a baseline. In those stimuli, the model did not execute any movement. The prototypes were evaluated according to the results of a motion tracking study, in which subjects listened to non-object-related action verbs, that is, the action verbs were presented without any context. They were asked to then spontaneously perform an arm and/or hand movement matching that verb (Weiss \& Müller, 2012b). The evaluation criteria can be found in Schaller et al. (in press). All videos were $6000 \mathrm{~ms}$ long. The mean duration of movements was $5497.4 \mathrm{~ms}(S D=554.0 \mathrm{~ms})$. Triggers were time-locked to the beginning of movements in the action videos and to the beginning of still baseline videos respectively. The videos were presented in a single block in fully randomized order.

\subsection{Procedure}

After instructions, participants were seated in a comfortable armchair about one meter away from a computer screen in an electromagnetically and sound shielded booth. The experiment was presented via a customized presentation software (Sculptor) running under Ubuntu (vers. 8.04.2). Sentences were fully randomized and split in three blocks including approximately the same number of sentences. There was one block of sentences in the beginning of each session, one in the middle, and one in the end. Videos were presented in fully randomized order in one block, which occurred after the first block of sentences for $50 \%$ of the subjects and after the second block of sentences for the other $50 \%$. A third set of stimuli not related to the current study was presented between the other two sentence blocks.

The sentences were presented aurally. A fixation cross appeared on the center of the screen $1000 \mathrm{~ms}$ before the beginning of each sentence and stayed on the screen throughout the entire trial. Subjects were instructed that they would not have to stare at the fixation cross all the time but that as soon as it appeared on the screen they should stop moving their body and eyes, minimize blinking, and prepare for the sentence to occur. $1000 \mathrm{~ms}$ after the end of each sentence, a beep signaled participants to verbally indicate whether they perceived the stimulus as a sensible sentence or not. They responded by saying YES if they judged the sentence to be sensible and by saying NO if they judged it to be nonsense. Simultaneously with the offset of the beep the fixation cross disappeared. After an ISI of 2000 ms the next trial started.

$2000 \mathrm{~ms}$ before the onset of each video a fixation cross appeared on the center of the screen. Participants were told that they should focus on the cross, stop moving their body and eyes, and minimize blinking. They were instructed to watch the video, which was presented in a visual angle of $7.4^{\circ}$, and to mentally mirror the presented action themselves or not to mirror an action in case of the still baseline videos. Parallel to the end of the video, the fixation cross popped up again and stayed on the screen for another $2000 \mathrm{~ms}$. After an ISI of $2000 \mathrm{~ms}$ the next trial started. Fig. 2 gives an example of trials in the sentence and the video condition.

\subsection{Recording}

Subject's EEG was recorded continuously from 27 active scalp electrodes mounted in an ActiCap (Brain Products Inc.), following the $10 / 20$ system with reference at the FCz. The left and right outer canthi were used to record horizontal eye movements (hEOG). To record vertical eye movements, one electrode was attached to the right infraorbital region (vEOG). The signal was amplified (QuickAmp, Brain Products Inc.) and digitized at a sampling rate of $1000 \mathrm{~Hz}$. A bandpass filter from 0.5 to $100 \mathrm{~Hz}$ and a $50 \mathrm{~Hz}$ notch filter were applied online. The BrainVision Recorder software (version 1.20, Brain Products Inc.) was used for recordings. Impedance was kept below $5 \mathrm{k} \Omega$ for all channels.

\subsection{Data preparation}

Data filtering, cleaning, and export was conducted with BrainVision Analyzer (version 2.0.1, Brain Products Inc.). Data of all channels was re-referenced against the mean of two earlobe electrodes. Semiautomatic artifact rejection was performed so that eye movements including blinks and abnormal trends became highlighted automatically but were again checked visually segment by segment, which allowed for a thorough artifact inspection. The following criteria were applied: the gradient should not exceed $50 \mu \mathrm{V} / \mathrm{ms}$; the difference between min and max voltage in the analyzed segment should not exceed $200 \mu \mathrm{V}$; the amplitude should not exceed $+200 \mu \mathrm{V}$ or fall below $-200 \mu \mathrm{V}$; the difference between min and max voltage in the analyzed segment should not be less than $0.1 \mu \mathrm{V}$. The proportion of data rejected as a consequence of the semiautomatic artifact rejection in the video condition was $21.8 \%$ with $22.5 \%$ in the still baseline condition and $21.1 \%$ in the action condition. $17.3 \%$ of data got rejected in the sentence trials, with $18 \%$ rejection of concrete action, $18.6 \%$ rejection of abstract action, and $15.3 \%$ rejection of abstract control stimuli. These relatively high values can be explained by taking into consideration that we presented complete sentences with a mean duration of about $1600 \mathrm{~ms}$. Subjects had difficulties to refrain from blinking for the entire segment, which lead to a high amount of eye blinks in the relevant epochs. We applied an additional bandpass filter from $0.5 \mathrm{~Hz}$ to $30 \mathrm{~Hz}$ to continuous EEG files.

\subsection{ERD analysis}

For both the sentence and the video stimuli, we conducted an ERD analysis for a central electrode cluster $\left(C_{3}, C_{z}, C_{4}\right)$ in a frequency range between 16 and $25 \mathrm{~Hz}\left(\beta_{2}\right)$. The chosen electrodes recorded activity over the hand areas on the motor strip (Moreno et al., 2013; Pfurtscheller et al., 1996) and were thus most likely to reflect motor activity during the processing of action stimuli. Pulvermüller, Mohr, and Schleichert (1999) also reported EEG activity around these electrodes while their participants perceived action related verbs and nouns in contrast to nouns with strong visual associations. The frequency range between 16 and $25 \mathrm{~Hz}$ was chosen due to the outcomes of Pfurtscheller et al. (1996), who observed the strongest $\beta$-ERD in a frequency range between 16 and $28 \mathrm{~Hz}$ during self-paced voluntary hand/wrist movements, and the studies of Moreno et al. (2013), and van Elk et al. (2010).

\subsubsection{Sentences}

According to the method described by Pfurtscheller and Lopes da Silva (1999), we first segmented the data in all sentence 


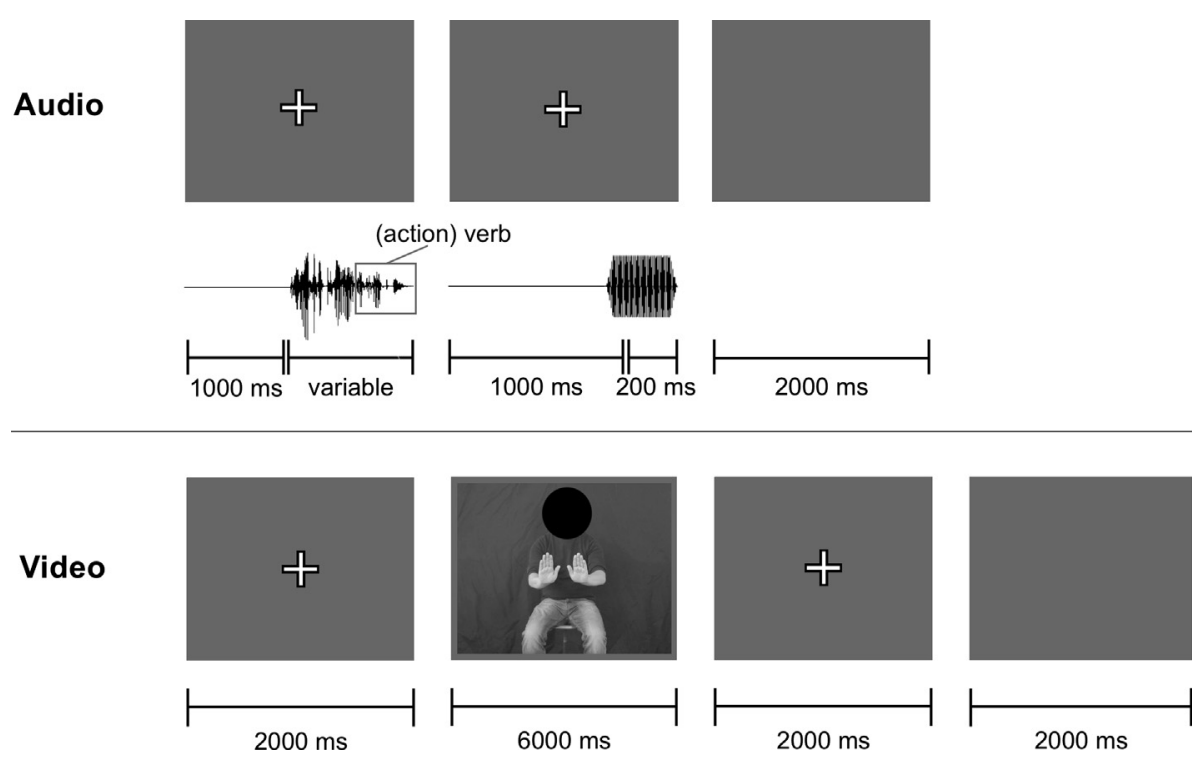

Fig. 2. Design of trials. Each trial started with a white fixation cross against a grey background, followed by the sentence or video respectively. In the sentence condition, the cross stayed on the screen throughout the presentation of the sentence and a successive interval of $1000 \mathrm{~ms}$ until a beep (duration $200 \mathrm{~ms}$ ) signaled participants to make their sensibility judgment. In the video condition, the cross popped back up after video presentation and stayed on the screen for another $2000 \mathrm{~ms}$. In both conditions there was an ISI of $2000 \mathrm{~ms}$.

conditions. We analyzed four different time slots: a baseline starting $-200 \mathrm{~ms}$ and lasting until $0 \mathrm{~ms}$ relative to sentence onset, a slot from $0 \mathrm{~ms}$ to $+400 \mathrm{~ms}$ relative to sentence onset, a slot from 0 to $1000 \mathrm{~ms}$ relative to noun onset, and a slot from 0 to $1600 \mathrm{~ms}$ relative to verb onset (Fig. 3). During the first and second time slot the sentences should not show any ERD differences, since the first time slot represented an interval before sentence onset and the second slot represented an interval during which all sentences were equal (I have.. .). We analyzed a time slot relative to the onset of the noun in order to compare possible ERD effects related to concrete vs. abstract nouns. The time slot chosen for the analysis of $\beta_{2^{-}}$ oscillation behavior during the verb was limited to $1600 \mathrm{~ms}$ due to the design of trials. There was a beep $1000 \mathrm{~ms}$ after sentence offset to signal participants that they might give their answer concerning the sensibility judgment. In the course of the experiment, we expected a readiness potential to develop a few hundred milliseconds before the beep. Verbs had a mean duration of about 730 ms. If the window chosen for the analysis of the verb would have been too long, the readiness potential might have been included in the time slot chosen for the analysis of the verb. We applied a filter of $16-25 \mathrm{~Hz}$ to the segmented epochs and subse-quently squared the amplitudes. These power samples were then averaged over all trials in each condition for each participant.

\subsubsection{Videos}

The data in the action condition was segmented in epochs from -200 to $+1600 \mathrm{~ms}$ relative to the onset of actions in the videos. Segments of +200 to 2000 ms relative to the onset of videos were chosen in the still baseline condition. We chose a different time window here because the mean onset time for actions in the action videos was $1450.4 \mathrm{~ms}$ post video onset. A comparison to the onset of the still baseline videos might therefore have led to significant differences between the two video conditions especially in the first $100-200 \mathrm{~ms}$, which could only be interpreted as effects based on the onset of a visual stimulus in the still condition. Subsequently, the same method as for the sentence trials was used.

\subsection{Statistical analysis}

Area mean amplitudes were calculated for each electrode in sequential windows of $200 \mathrm{~ms}$ in the selected epochs. Amplitudes were averaged over the relevant electrodes for each sentence and video type in each time window. Since in most of the time slots the data was not normally distributed, we conducted non parametric statistical testing (Field, 2009). In the sentence condition, the three sentence types concrete action, abstract action, and abstract were analyzed in Friedman-tests. In case of significant results, post-hoc Wilcoxon-tests were used. Concrete and abstract nouns as well as the two video types action and still were compared by means of Wilcoxon-tests.

\section{Results}

\subsection{Sentences}

The mean power did not differ significantly between the three sentence types during neither the baseline nor the sentence onset epochs. Further, the analysis of concrete vs. abstract nouns did not show any significant differences between the two noun types. For the interval between $1200 \mathrm{~ms}$ and $1400 \mathrm{~ms}$ after verb onset the Friedman statistics revealed $\beta_{2}$-desynchronization for concrete action and abstract action stimuli in comparison to the abstract

\begin{tabular}{c|l|l|l}
$\begin{array}{c}\text { BASELINE } \\
200 \mathrm{~ms}\end{array}$ & $\begin{array}{c}\text { BEGINNING OF SENTENCE } \\
400 \mathrm{~ms}\end{array}$ & \multicolumn{1}{c}{$\begin{array}{c}\text { NOUN } \\
1000 \mathrm{~ms}\end{array}$} & \multicolumn{1}{c}{$\begin{array}{c}\text { VERB } \\
1600 \mathrm{~ms}\end{array}$} \\
\hline & $\begin{array}{l}\text { Ich habe (die) } \\
\text { */ have (the) }\end{array}$ & $\begin{array}{l}\text { Handbremse } \\
\text { hand break }\end{array}$ & $\begin{array}{l}\text { gezogen. } \\
\text { drawn. }\end{array}$
\end{tabular}

Fig. 3. Intervals chosen for the ERD-analysis. Nouns had a mean duration of $434 \mathrm{~ms}$. The analyzed interval of $1000 \mathrm{~ms}$ post noun onset thus overlapped with the onset of the verb. 
items, $\chi^{2}(2)=7.923, p<0.05$. As shown by post-hoc pairwise comparisons, the mean power during both concrete action and abstract action stimulus processing was significantly lower than the mean power during abstract item processing. The respective results are $z$ $=-2.679, p<0.01$ one-sided for the comparison of concrete action and abstract items and $z=-1.918, p<0.05$ one-sided for the comparison of abstract action and abstract items. For the subsequent time slot between 1400 and 1600 ms post verb onset, the Friedmantest was significant as well with $\chi^{2}(2)=11.077, p<0.01$. The mean power during the processing of abstract action items was significantly lower than during the processing of concrete action items, $z=-2.400, p<0.01$ one-sided. Further, and of more interest for the current study, the comparison between abstract action and abstract stimuli revealed a significant effect with the power during abstract action verb processing being lower than during abstract verb processing, $z=-1.892, p<0.05$ one-sided. More values concerning the test results may be found in Table 1. Figs. 4 and 5 show the course of $\beta_{2}$-power during the processing of the three sentence types.

\subsection{Videos}

Whereas there was no significant effect concerning power differences between action and still videos during the baseline, results showed clear $\beta_{2}$-desynchronization while participants watched videos showing actions in comparison to the still video condition. The mean power values during action observation were significantly lower than the values during the observation of a still video. This effect started $400 \mathrm{~ms}$ after action onset and lasted throughout the analyzed epoch. The results of all statistical tests comparing the two video conditions can be found in Table 1. Fig. 6 displays the course of $\beta_{2}$-power while participants were watching the two video types.

\section{Discussion}

In the current study, we compared electrophysiological brain responses during action observation and the processing of action verbs in concrete and abstract contexts. We analyzed $\beta_{2}$-rhythm behavior as these oscillations have repeatedly been reported to be strongly related to neural sensorimotor processes. EEG responses on action observation compared to a still video baseline revealed an action related $\beta_{2}$-suppression between 400 and $1600 \mathrm{~ms}$ post action onset, which was present in a central electrode cluster. The processing of action related sentences containing action verbs in either a concrete or an abstract context elicited a comparatively late effect, starting about $1200 \mathrm{~ms}$ post action verb onset. However, mean power during action verb processing in both contexts was significantly more negative than in the abstract control condition.

Our findings concerning $\beta_{2}$-suppression during action observation are in line with previous studies reporting the same effects during both action observation and imagery. McFarland et al.(2000) analyzed $\mu-(8-12 \mathrm{~Hz})$ and $\beta$-suppression $(18-25 \mathrm{~Hz})$ while participants either repeatedly opened and closed their hand or imagined doing so. They reported similar oscillation patterns for the two conditions, that is, a desynchronization during action execution and action imagery in both frequency bands. The effect in

Table 1

Statistical results for the Friedman- and Wilcoxon-tests in the analyzed time slots for a central electrode cluster $\left(C_{3}, C_{z}, C_{4}\right)$ in the frequency range $16-25$ Hz (CA: concrete action, AA: abstract action, A: abstract). The CA-value in the time slot for the noun represents the value for concrete nouns and the AA-value represents the value for abstract nouns. The table shows the values for the mean power $\left(\mu \mathrm{V}^{2}\right)$, the chi-square $\left(\chi^{2}\right)$ for the Friedman- and the $z$-scores for the Wilcoxon-tests respectively, as well as the $p$-values of the test statistic. Significant results are printed in bold. Degrees of freedom for each Friedman-test were $d f=2$.






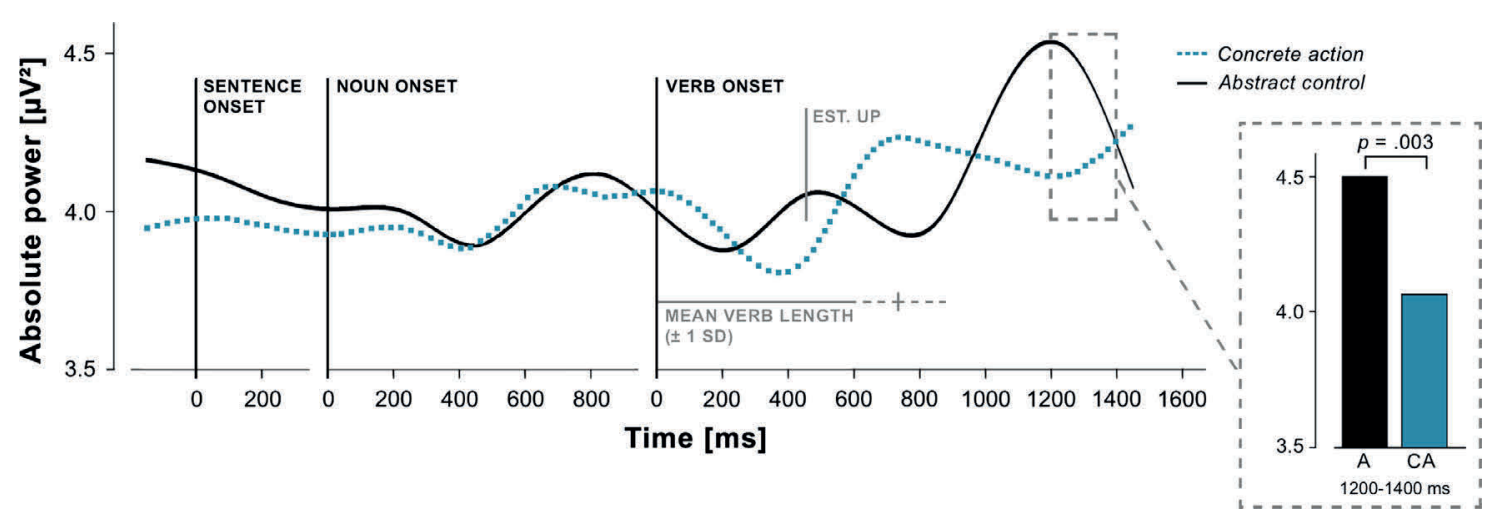

Fig. 4. Mean power changes $\left[\mu \mathrm{V}^{2}\right]$ during the processing of concrete action $(\mathrm{CA})$ and abstract control $(\mathrm{A})$ sentences in the $\beta_{2}$-frequency range. Significant differences were found in the time slot between 1200 and 1400 ms post verb onset. The uniqueness point of verbs (EST. UP) was estimated as being around 450 ms.

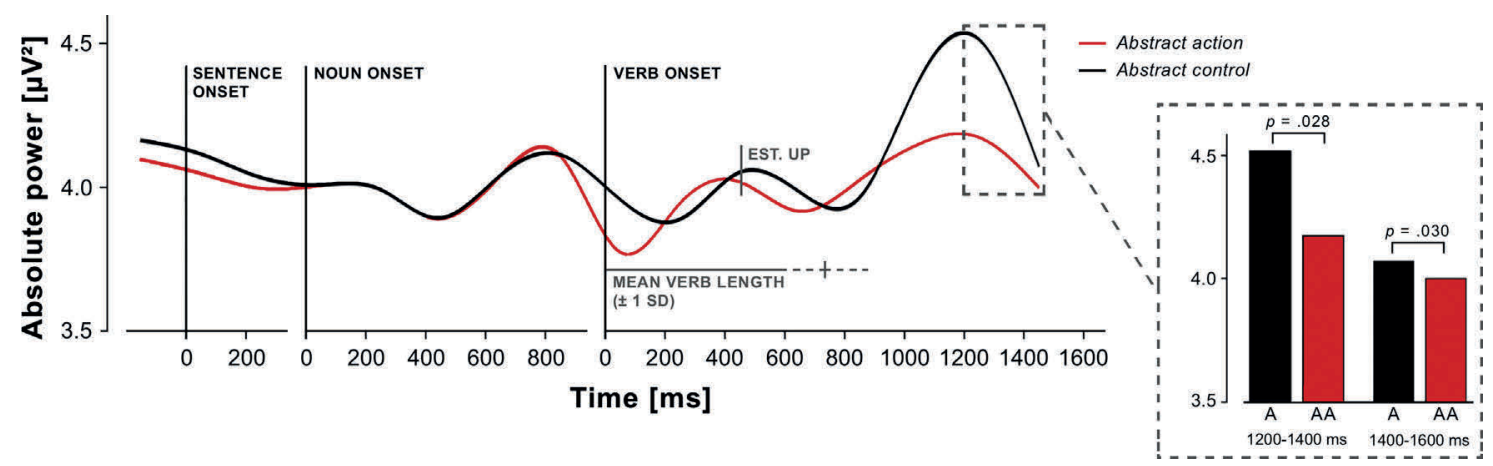

Fig. 5. Mean power changes $\left[\mu \mathrm{V}^{2}\right]$ during the processing of abstract action (AA) and abstract control $(\mathrm{A})$ sentences in the $\beta_{2}$-frequency range. Significant differences were found in the last two time slots post verb onset. The uniqueness point of verbs was estimated as being around $450 \mathrm{~ms}$.

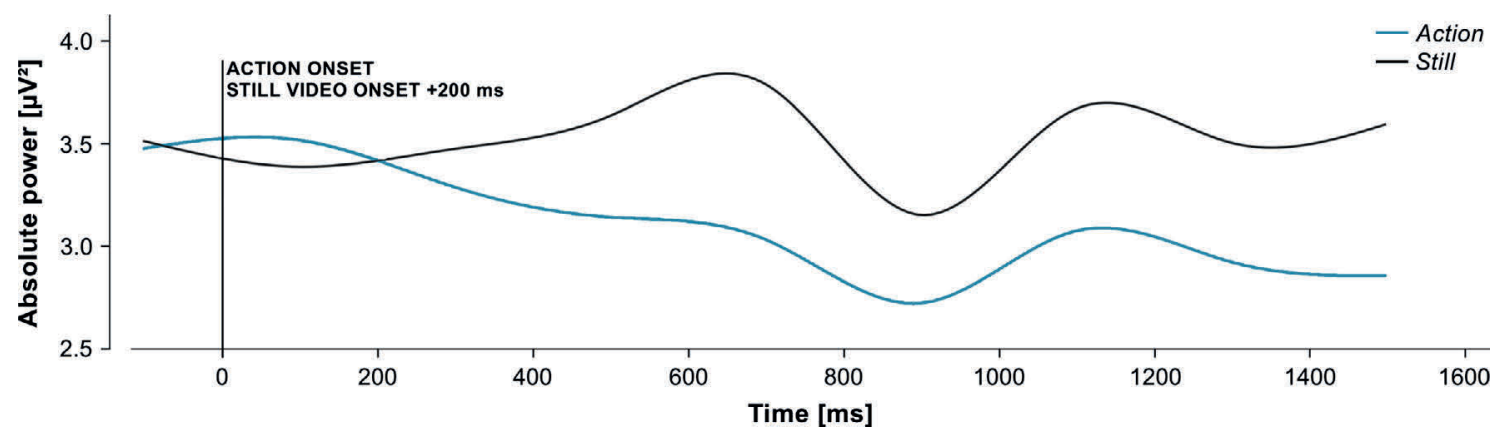

Fig. 6. Mean power changes $\left[\mu \mathrm{V}^{2}\right]$ during the processing of the two video types in the $\beta_{2}$-frequency range. A clear desynchronization can be seen for action compared to still videos, starting $400 \mathrm{~ms}$ post action onset.

the $\mu$-range was most prominent at lateral postcentral electrodes. $\beta$-range ERD showed a rather diffuse pattern with its focus at the vertex. In an MEG study by De Lange, Jensen, Bauer, and Toni (2008), participants had to indicate whether a line drawing of a hand varying in its rotation displays a left or a right hand. This task was supposed to elicit mental motor imagery and simulation. The authors observed strong $\mu-(8-12 \mathrm{~Hz})$ and $\beta$-suppression (16$24 \mathrm{~Hz}$ ) over parieto-occipital and precentral sensors. Action observation was analyzed by Moreno et al. (2013) and Simon and Mukamel (2016). In both studies, $\mu$ - and $\beta$-ERD could be observed while participants were watching videos of hand movements. An interesting observation by Quandt and Marshall (2014) was that if participants gained sensorimotor experience with objects, the intensity of $\mu$ - and $\beta$-suppression was stronger when watching the same objects being manipulated in a video recording than if participants did not have the chance to gain sensorimotor information about the objects. This is in line with the results reported by Järveläinen et al. (2004) that motor-related brain oscillation patterns might be sensitive to the experience participants obtained with the relevant objects. In the current study, we found $\beta_{2}$-ERD over central electrodes during the observation of prototypical actions, which further supports the assumption that action observation leads to the activation of motor representations and possibly elicits action simulation processes.

The current results showed no $\beta_{2}$-related differences during the processing of concrete vs. abstract nouns. Oscillations in the $\beta$-range have previously been described as being sensitive towards the concrete-abstract distinction. For instance, Weiss and Müller (2013) described stronger mean coherence during the processing of concrete compared to abstract sentences in theta $(3-7 \mathrm{~Hz})$ and 
$\beta_{1}$-frequencies (13-18 Hz). Weiss and Rappelsberger (1996) compared concrete to abstract nouns and reported differences related to intra- and interhemispheric coherence changes in $\beta_{1}$-frequencies between the two word types. Here, we analyzed $\beta_{2}$-oscillations in response to concrete vs. abstract nouns. There are several possible reasons for why we could not see any difference effects between the two noun types. First, possible effects might have been covered by verb comprehension processes. Nouns in the current study had a mean duration of about $434 \mathrm{~ms}$. The analyzed interval of $1000 \mathrm{~ms}$ post noun onset thus overlapped with the onset of subsequently presented verbs for a mean duration of $566 \mathrm{~ms}$. Second, the results of earlier studies showed effects in $\beta_{1}$ - and not in $\beta_{2}$-frequencies. Possibly, $\beta_{2}$-oscillations are not as sensitive towards the concreteabstract distinction as $\beta_{1}$-oscillations. Third, we only analyzed a central electrode cluster over the motor strip, which might not have been large enough to reflect possible power differences between concrete and abstract nouns in the analyzed frequency range. Thus, in order to find out about a possible sensitivity of $\beta_{2^{-}}$ oscillations towards the concrete-abstract distinction, a study specifically focused on that question could lead to more informative results.

Possibly, the difference in the cloze-probability between the sentences needs to be considered as a caveat when interpreting the current data since it might have influenced the results. According to van Elk et al. (2010), effects of cloze-probability might influence $\beta$-ERD in a frequency range between 20 and $30 \mathrm{~Hz}$ in the time interval of the N400. They detected that $\beta$-ERD was stronger for noun-verb pairs with a high cloze-probability. Hence, if the cloze-probability of the sentences would have influenced $\beta$-ERD in the current study, the effects should have been stronger for the action sentences than the abstract control sentences in the N400 time window, which we did not observe. Further, the sentence-related effects observed here resemble those during action observation, suggesting that the underlying mechanisms are similar. Although it is, therefore, considered unlikely, an influence of the differences concerning the cloze-probability of the noun-verb pairs in the stimuli used here cannot be completely ruled out. A partial replication of the current study, in which the cloze-probability between other different sentence types is matched, might serve the robustness of the current effects.

The main focus of the current study was on the comparison of meaning constitution processes related to action verbs in concrete and abstract contexts. Compared to abstract control sentences not containing action verbs, we observed significantly lower power values in the $\beta_{2}$-frequency range for action verbs in both concrete and abstract contexts. The onset of this effect was $1200 \mathrm{~ms}$ post verb onset and about $465 \mathrm{~ms}$ after mean verb offset. This latency appears to be quite high, especially when taking the suggestions by Pulvermüller, Shtyrov, and Hauk (2009) into account. They discussed the possibility of an almost simultaneous access to all cognitive information related to a linguistic sign. According to them, this access should take place between 100 and $250 \mathrm{~ms}$ after stimulus onset. However, they further discuss that later EEG components might either reflect a second comprehension step or postcomprehension processes (Pulvermüller et al., 2009). In studies by Pulvermüller, Härle, and Hummel (2001) and Klepp, Niccolai, Buccino, Schnitzler, and Biermann-Ruben (2015), effects concerning brain responses to action language stimuli were also reported as early as $250 \mathrm{~ms}$ and $400-600 \mathrm{~ms}$ post action verb onset. It needs to be taken into account, though, that these studies firstly presented single action verbs not embedded in a sentence context. The activation of sensorimotor areas might occur later if action verbs are presented as part of a sentence since the allover comprehension time is prolonged. Secondly, Pulvermüller et al. (2001) did not analyze a specific frequency range but focused on ERP differences between electrodes. Thirdly, only the study by Klepp et al.
(2015) used abstract verbs as a comparative condition. These methodological differences need to be considered when comparing the current results to those of earlier studies. Here, in relation to the ERD detected during action observation, the onset of the verb effect was rather late but could still be interpreted as a late ERD. One reason for the effect occurring rather late might be the frequency range chosen for the analysis in the current study. As Pfurtscheller et al. (1996) discussed, they observed the strongest $\beta$ ERD in a frequency range between 16 and $28 \mathrm{~Hz}$ during self-paced voluntary hand/wrist movements. This is about the frequency range we chose for the current analysis. It might be possible, though, that a more fine-grained approach and an analysis of smaller frequency steps might result in the current effects becoming more prominent. However, a combined ERP and spectral analysis conducted by Pulvermüller, Lutzenberger, and Preissl (1999) indicated a rather late responsiveness of EEG oscillations between 25 and $35 \mathrm{~Hz}$ to action verbs as well. They presented concrete nouns and action verbs to participants and focused on comparing ERD and spectral differences in occipital and central electrode sites. Whereas the ERP analysis revealed a significant word class effect between the two electrode sites as early as $200-230$ ms post stimulus onset, the spectral analysis showed a significant interaction between the regions of interest and word class around $30 \mathrm{~Hz}$ in a later time window between 500 and 800 ms post stimulus onset. In this interval, Pulvermüller, Lutzenberger, et al. (1999) reported enhanced activity at central sites following action verb compared to noun presentation. The authors discussed that this late difference in higher frequencies might go back on active memory processes. After the activation of cell assemblies induced by stimulus presentation, which is visible as an early ERP, this activity might sustain and show as a change in high-frequency responses (Pulvermüller, Lutzenberger, et al., 1999). In the context of the data presented here, this might indicate that the late effects are not directly linked to language processing but rather to active memory processes in motor areas. It is, however, interesting that these processes occurred for action verbs in both concrete and abstract contexts but not for abstract verbs. Note that participants were asked to perform different tasks in the two experimental blocks. While watching the action videos, they were instructed to actively imagine executing the actions themselves. When listening to the sentences, they were supposed to perform a sensibility judgment task. Possibly, shifting participants' focus from imagining execut-ing the perceived action to the sensibility of the sentence content caused a higher latency until the onset of oscillatory patterns related to sensorimotor processes. Further, whereas the actions in the videos were performed without any object being present, the context of the sentences suggested object-related actions, which is another criterion possibly causing the difference in the onset latencies between the two tasks. Incidentally, the late onset of the effect may be relativized. Note that we presented sentences in the present perfect (German Perfekt) with the verb at the sentences' final position. Several studies suggested a syntactic complexity effect, describing that comprehension processes take more time in correlation with an increase of syntactic complexity (Carpenter, Miyake, \& Just, 1995; Ferreira, 1991; King \& Just, 1991; Schriefers, Friederici, \& Kühn, 1995; Wingfield, Peelle, \& Grossman, 2003). Ferreira (1991) asked participants to memorize sentences which differed in syntactic complexity, defined as the number of nodes in a phrase structure tree. The initiation time of participants' response increased with an increase of syntactic complexity (Ferreira, 1991). King and Just (1991) contrasted subject-relative (The reporter that attacked the senator admitted the error publicly after the hearing.) to object-relative clauses (The reporter that the senator attacked admitted the error publicly after the hearing.) in a Reading Span task. Reading times were prolonged for objectrelative in comparison to subject-relative sentences inde- 
pendently of the reading span capacity of subjects. Syntactic structure in the current study was more complex than in studies presenting single words or sentences in the present tense, which might have caused a comparably late access to the meaning of the sentence final action verb. Further, one needs to consider the uniqueness point (UP) of the verbs. In the cohort model, the UP is defined as the point at which sufficient phonetic information of a word is available to identify the word (Marslen-Wilson, 1987). In the current experiment, the UP of the verb was prolonged due to final verbs being presented as participles, thus starting with a prefix (e.g., ge-), which did not give any information about the content of the verb. This very short prefix had a mean duration of about $110 \mathrm{~ms}$. Given that the mean duration of the final verbs was $735 \mathrm{~ms}$ and that they comprised three syllables on average, the mean duration of syllables except for the prefix was about $310 \mathrm{~ms}$. Assuming that the UP of the verbs would be somewhere after the end of the second syllable, we suggest it to be about $450 \mathrm{~ms}$ post final verb onset in the current study. Accordingly, the latency from the current UP until the onset of the observed desynchronization was about $750 \mathrm{~ms}$, which relativizes the lateness of the effect.

To our knowledge, there have only been two studies focusing on $\beta$-suppression during action language processing so far. van Elk et al. (2010) reported $\beta$-ERD during action verb processing in a frequency range between 20 and $30 \mathrm{~Hz}$ with a latency of $500 \mathrm{~ms}$. However, they did not compare ERD effects in comparison to a neutral non-action baseline, as was done in the current study. The approach by Moreno et al. (2013) is more comparable to the material and analysis used here, since concrete action sentences were contrasted with abstract sentences. They analyzed $\mu$ - and $\beta$-power during verb processing by means of an FFT-analysis. In contrast to the current method, they chose segments with a length of $2 \mathrm{~s}$. No accurate information on the latency of the effect in the $\beta$-range could be gained. The current study thus provides information on the latency of $\beta$-ERD during action verb processing compared to a neutral non-action baseline for the first time. Nevertheless, it needs to be considered that the effect might not reflect processes of meaning constitution but that it rather is an indicator of motor imagery or simulation processes triggered by action verb comprehension. Thus, the observed effect would not go back on motor representations being activated due to semantic processing of the sentence but rather due to simulation processes evoked as an after-effect of semantic processing. However, in a study by Andres, Finocchiaro, Buiatti, and Piazza (2015) the design allowed to assign the data to different stages of semantic decoding. Their results indicated that motor related electrophysiological brain responses on linguistic action stimuli are indeed related to semantic processing. Further, it needs to be highlighted that the similarity regarding $\beta_{2}$-ERD as a response to action observation and to action language processing is limited concerning both the latency and the magnitude of the effect. This might indicate that motor representations are involved in action language processing only to a limited degree.

Given that the observed $\beta$-ERD is interpreted as an indicator of motor involvement in action language processing, this effect is in line with results of a current behavioral study by Schaller et al. (in press). They observed a cross-modal priming effect of prototypical actions on action verb comprehension in concrete and abstract contexts. Participants executed action prototypes for certain action verbs or actions that were unrelated to the action verbs and subsequently listened to the same sentences that were presented in the current study. Thus, sentence stimuli either contained the corresponding action verb in a concrete or an abstract context. Response times were collected by means of a sensibility judgment. The authors reported that participants were faster to respond to concrete action sentences (I have pulled the hand break.) after the exe- cution of a prototypical action than after the execution of an unrelated movement. For the abstract action sentences (I have drawn the consequence.), the execution of both related and unrelated actions caused a facilitation effect. These results are interpreted as indicating differences in the degree or quality of the involvement of the retrieved motor representations in action verb comprehension in concrete compared to abstract contexts. Whereas action verbs in literal sentences might elicit a very detailed motor representation, the comprehension of action verbs in abstract sentences might be related to a rather broad motor representation (Schaller et al., in press).

An alternative explanation for the ERD-differences between action and abstract sentence-final verbs might be that participants responded by giving a verbal answer. As Borghi and Zarcone (2016) reported, processing abstract words elicited activation of the mouth area, whereas concrete words activated sensorimotor representations in their behavioral study. They compared responses on concrete and abstract words primed by a concrete or an abstract word definition in terms of a go-nogo paradigm. Improper combinations of definitions and words did not require a response by participants, whereas appropriate combinations required them to press a button. In one experimental block they pressed the button with their hand, in a second block they used their teeth. Borghi and Zarcone (2016) reported a general advantage of hand over mouth responses. However, this advantage was less prominent for responses following abstract than concrete target words. This finding is in line with previous results by Scorolli et al. (2011), w h o postulated that abstract concepts might be processed stronger in language areas whereas concrete words might rely more on the sensorimotor system. Against the background of these results, the difference in $\beta$-ERD modulation observed between abstract and action words in the current study might be due to the interaction of the mouth area activated during abstract verb processing and the verbal response. Several aspects speak against such an interpretation. First, after verb offset there was a silent interval of $1000 \mathrm{~ms}$, then a tonal signal of $200 \mathrm{~ms}$ and the verbal response was required only thereafter. Since the ERD-effect occurred about $465 \mathrm{~ms}$ after verb offset, more than $700 \mathrm{~ms}$ passed between the effect and the verbal response. Second, independently of a possible interaction of abstract verbs and the verbal response, action verbs in abstract contexts were similar to those in concrete contexts, which is what we were focusing on in the current study. Third, the ERD-effect matches the behavioral results of Schaller et al. (in press), in which response times on abstract sentences contain-ing action verbs were influenced by preceding action execution whereas response times on abstract control stimuli were not. Taken together, these arguments speak against the assumption that the verbal response had an influence on the effects observed here.

Our current findings are further in accordance with results of other studies proposing a gradual involvement of motor representations in abstract action language processing (Desai et al., 2011, 2013; Romero Lauro et al., 2013; Sakreida et al., 2013; Troyer, Curley, Miller, Saygin, \& Bergen, 2014). Desai et al. (2011) compared brain activation patterns in response to arm/hand related action verbs, which were embedded in literal and metaphoric contexts. They found that both sentence types elicited activation in the anterior inferior parietal lobule (aIPL) in the left hemisphere to the same degree. During the processing of metaphoric action stimuli, an activation of the right aIPL in addition to other areas related to abstract language processing was observed. They further reported that the involvement of sensorimotor areas in action metaphor comprehension is gradual, with a stronger involvement during the comprehension of more unfamiliar metaphors. In a later study, Desai et al. (2013) added idiomatic action sentences to the stimulus set used in the previous study. They observed activation 
in secondary motor areas in the IPL, small activation clusters in primary motor cortex and in temporal regions for both literal and metaphoric stimuli but not for idiomatic sentences, which further supported the idea of a gradual involvement. In an fMRI study by Romero Lauro et al. (2013), similar results were obtained, supporting the view that the involvement of motor areas in action language processing is gradual, ranging from strong in literal stimuli to weak or no involvement in idiomatic sentences (Romero Lauro et al., 2013). Alternatively, it has been suggested that concrete and abstract concepts both rely on sensorimotor systems but beyond that abstract words evoke more emotional and linguistic representations (Borghi, Capirci, Gianfreda, \& Volterra, 2014; Scorolli et al., 2012).

An interesting finding in the current study was that the ERD during abstract action verb processing compared to the abstract control condition was detectable over a time interval of $400 \mathrm{~ms}$, that is, between 1200 and 1600 ms post action verb onset. In contrast, the ERD during concrete action verb processing was present between 1200 and $1400 \mathrm{~ms}$ post action verb onset only. These results speak in favor of the assumption that motor representations are retrieved to a different degree or in a different manner during abstract compared to concrete action verb processing. We would not interpret the sustained abstract action effect as an indicator of a stronger involvement of motor representations in abstract than in concrete action verb processing. Rather, the integration of motor information in the abstract context takes more time than in the concrete context. This might be because only some of the motor information expressed by the action verb is relevant for decoding the meaning of the abstract action sentence. This relevant motor information needs to be selected and transferred on an abstract level of meaning. For instance, when processing the sentence "I have drawn the consequence.", relevant motor information to comprehend the meaning of the abstract sentence might be the force of drawing, which can be quite strong, or the direction of the movement, which represents that the act of drawing affects the person who is drawing (e.g., object might be easier to see/grasp/ handle). The sustained $\beta$-ERD during abstract action verb processing probably reflects the higher effort needed for the selection and integration of the relevant motor information into the abstract context. Thus, our current results support the assumption of a gradual involvement of motor representations in action language processing. Probably all of the sensorimotor information of an action is relevant and therefore accessed during the process of meaning constitution of action verbs in concrete contexts. In contrast, if the meaning of an abstract action sentence is generated, only parts of the sensorimotor information connected to an action is relevant.

\section{Conclusion}

In the current study we analyzed oscillations in the $\beta_{2}$-range $(16-25 \mathrm{~Hz})$ of the human EEG in response to action observation as well as concrete and abstract action language processing against the background of the embodied language theory. Findings of previous studies suggested that $\beta_{2}$-oscillations might be sensitive to action language but did not reveal any precise temporal information regarding the onset of respective effects. Here, we found $\beta_{2}-$ desynchronization in response to the presentation of action verbs embedded in concrete and abstract contexts. This effect occurred about $450 \mathrm{~ms}$ post mean action verb offset and speaks in favor of motor representations being involved in the process of meaning constitution not only during concrete but also during abstract action language. The current results thus provide information on the latency of $\beta$-ERD during action verb processing compared to a neutral non-action baseline for the first time. Further, they sup- port the assumption that the involvement of motor representations in language processing is gradual, which is in accordance with findings from other recent studies.

\section{Acknowledgments}

This research was supported by the Cluster of Excellence Cognitive Interaction Technology 'CITEC' (EXC 277) at Bielefeld University, which is funded by the German Research Foundation (DFG).

\section{References}

Alemanno, F., Houdayer, E., Cursi, M., Velikova, S., Tettamanti, M., Comi, G., \& Leocani, L. (2012). Action-related semantic content and negation polarity modulate motor areas during sentence reading: An event-related desynchronization study. Brain Research, 1484, 39-49. http://dx.doi.org/ desynchronization study. Brain

Andres, M., Finocchiaro, C., Buiatti, M., \& Piazza, M. (2015). Contribution of motor representations to action verb processing. Cognition, 134, 174-184. http://dx. doi.org/10.1016/j.cognition.2014.10.004.

Baker, S. N. (2007). Oscillatory interactions between sensorimotor cortex and the periphery. Current Opinion in Neurobiology, 17, 649-655. http://dx.doi.org/ 10.1016/j.conb.2008.01.007.

Barsalou, L. W. (1999). Perceptual symbol systems. Behavioral and Brain Sciences, 22, 577-660.

Barsalou, L. W. (2008). Grounded cognition. Annual Review of Psychology, 59, 617-645. http://dx.doi.org/10.1146/annurev.psych.59.103006.093639.

Bastiaansen, M., Magyari, L., \& Hagoort, P. (2010). Syntactic unification operations are reflected in oscillatory dynamics during online sentence comprehension. Journal of Cognitive Neuroscience, 22, 1333-1347.

Borghi, A. M., Capirci, O., Gianfreda, G., \& Volterra, V. (2014). The body and the fading away of abstract concepts and words: A sign language analysis. Frontiers in Psychology, 5, 1-13. http://dx.doi.org/10.3389/fpsyg.2014.00811.

Borghi, A. M., \& Zarcone, E. (2016). Grounding abstractness: Abstract concepts and the activation of the mouth. Frontiers in Psychology, 7, 1498.

Boulenger, V., Hauk, O., \& Pulvermuller, F. (2009). Grasping ideas with the motor system: Semantic somatotopy in idiom comprehension. Cerebral Cortex, 19(8), 1905-1914. http://dx.doi.org/10.1093/cercor/bhn217.

Buccino, G., Colagè, I., Gobbi, N., \& Bonaccorso, G. (2016). Grounding meaning in experience: A broad perspective on embodied language. Neuroscience $\mathcal{E}$ Biobehavioral Reviews, 69, 69-78. http://dx.doi.org/10.1016/j. neubiorev.2016.07.033.

Carpenter, P. A., Miyake, A., \& Just, M. A. (1995). Language comprehension: Sentence and discourse processing. Annual Review of Psychology, 46, 91-120.

D’Ausilio, A., Pulvermüller, F., Salmas, P., Bufalari, I., Begliomini, C., \& Fadiga, L. (2009). The motor somatotopy of speech perception. Current Biology, 19, 381-385. http://dx.doi.org/10.1016/j.cub.2009.01.017.

Davidson, D. J., \& Indefrey, P. (2007). An inverse relation between event-related and time-frequency violation responses in sentence processing. Brain Research, 1158, 81-92.

De Lange, F. P., Jensen, O., Bauer, M., \& Toni, I. (2008). Interactions between posterior gamma and frontal alpha/beta oscillations during imagined actions. Frontiers in

Human Neuroscience, 2, 1-12. http://dx.doi.org/10.3389/neuro.09.007.2008. Desai, R. H., Binder, J. R., Conant, L. L., Mano, Q. R., \& Seidenberg, M. S. (2011). The neural career of sensory-motor metaphors. Journal of Cognitive Neuroscience, 23, 2376-2386. http://dx.doi.org/10.1162/jocn.2010.21596.

Desai, R. H., Binder, J. R., Conant, L. L., \& Seidenberg, M. S. (2010). Activation of sensory-motor areas in sentence comprehension. Cerebral Cortex, 20(2) 468-478. http://dx.doi.org/10.1093/cercor/bhp115.

Desai, R. H., Conant, L. L., Binder, J. R., Park, H., \& Seidenberg, M. S. (2013). A piece of the action: Modulation of sensory-motor regions by action idioms and metaphors. NeuroImage, 83, 862-869. http://dx.doi.org/10.1016/j. neuroimage.2013.07.044.

Fargier, R., Paulignan, Y., Boulenger, V., Monaghan, P., Reboul, A., \& Nazir, T. A. (2012). Learning to associate novel words with motor actions: Languageinduced motor activity following short training. Cortex, 48, 888-899. http://dx. doi.org/10.1016/j.cortex.2011.07.003.

Ferreira, F. (1991). Effects of length and syntactic complexity on initiation times for prepared utterances. Journal of Memory and Language, 30, 210-233.

Field, A. (2009). Discovering statistics using SPSS (3rd ed.). London: Sage.

Fischer, M. H., \& Zwaan, R. A. (2008). Embodied language: A review of the role of the motor system in language comprehension. The Ouarterly Journal of Experimental Psychology, 61(6), 825-850. http://dx.doi.org/10.1080/17470210701623605.

Gallese, V., \& Lakoff, G. (2005). The brain's concepts: The role of the sensory-motor system in conceptual knowledge. Cognitive Neuropsychology, 22(3-4), 455-479. http://dx.doi.org/10.1080/02643290442000310.

Glenberg, A. M., \& Kaschak, M. P. (2003). The body's contribution to language. The Psychology of Learning and Motivation, 43, 93-126.

Glenberg, A. M., Lopez-Mobilia, G., McBeath, M., Toma, M., Sato, M., \& Cattaneo, L. (2010). Knowing beans: Human mirror mechanisms revealed through motor adaptation. Frontiers in Human Neuroscience, 4, 1-6. http://dx.doi.org/10.3389/ fnhum.2010.00206. 
Glenberg, A. M., Sato, M., Cattaneo, L., Riggio, L., Palumbo, D., \& Buccino, G. (2008). Processing abstract language modulates motor system activity. The Quarterly Journal of Experimental Psychology, 61, 905-919. http://dx.doi.org/10.1080/ 17470210701625550

Hari, R., Bourguignon, M., Piitulainen, H., Smeds, E., De Tie'ge, X., \& Jousmäki, V. (2014). Human primary motor cortex is both activated and stabilized during observation of other person's phasic motor actions. Philosophical Transactions of the Royal Society B, 369, 20130171. http://dx.doi.org/10.1098/rstb.2013.0171.

Hari, R., Forss, N., Avikainen, S., Kir Veskari, E., Salenius, S., \& Rizzolatti, G. (1998). Activation of human primary motor cortex during action observation: A neuromagnetic study. Proceedings of the National Academy of Science USA, 95, 15061-15965.

Hauk, O., Johnsrude, I., \& Pulvermüller, F. (2004). Somatotopic representation of action words in human motor and premotor cortex. Neuron, 41, 301-307.

Herrmann, W. M., Fichte, K., \& Kubicki, S. (1980). Definition von EEGFrequenzbändern aufgrund strukturanalytischer Betrachtungen. In S. Kubicki, W. M. Herrmann, \& G. Laudahn (Eds.), Faktorenanalyse und Variablenbildung aus dem Elektroenzephalogramm (pp. 61-74). New York: Fischer.

Järveläinen, J., Schürmann, M., \& Hari, R. (2004). Activation of the human primary motor cortex during observation of tool use. Neurolmage, 23, 187-192. http:// dx.doi.org/10.1016/j.neuroimage.2004.06.010.

King, J., \& Just, M. A. (1991). Individual differences in syntactic processing: The role of working memory. Journal of Memory and Language, 30, 580-602.

Klatzky, R. L., Pellegrino, J. W., McCloskey, B. P., \& Doherty, S. (1989). Can you squeeze a tomato? The role of motor representations in semantic sensibility judgments. Journal of Memory and Language, 28, 56-77.

Klepp, A., Niccolai, V., Buccino, G., Schnitzler, A., \& Biermann-Ruben, K. (2015). Language-motor interference reflected in MEG beta oscillations. NeuroImage 109, 438-448. http://dx.doi.org/10.1016/j.neuroimage.2014.12.077.

Kuhlmann, W. N. (1978). Functional topography of the human mu rhythm. Electroencephalography and Clinical Neurophysiology, 44, 83-93.

Luo, Y., Zhang, Y., Feng, X., \& Zhou, X. (2010). Electroencephalogram oscillations differentiate semantic and prosodic processes during sentence reading. Neuroscience, 169, 654-664.

Marslen-Wilson, W. D. (1987). Functional parallelism in spoken word-recognition. Cognition, 25, 71-102.

McFarland, D., Miner, L. A., Vaughan, T. M., \& Wolpaw, J. R. (2000). Mu and beta rhythm topographies during motor imagery and actual movements. Brain Topography, 12, 177-186.

Moreno, I., de Vega, M., \& León, I. (2013). Understanding action language modulates oscillatory mu and beta rhythms in the same way as observing actions. Brain and Cognition, 82, 236-242. http://dx.doi.org/10.1016/j.bandc.2013.04.010.

Moreno, I., de Vega, M., León, I., Bastiaansen, M., Glen Lewis, A., \& Magyari, L. (2015). Brain dynamics in the comprehension of action-related language. A timefrequency analysis of mu rhythms. Neurolmage, 109, 50-62. http://dx.doi.org/ 10.1016/j.neuroimage.2015.01.018.

Moseley, R. L., \& Pulvermüller, F. (2014). Nouns, verbs, objects, actions, and abstractions: Local fMRI activity indexes semantics, not lexical categories. Brain and Language, 132, 28-42. http://dx.doi.org/10.1016/j.bandl.2014.03.001.

Oldfield, R. C. (1971). The assessment and analysis of handedness: The Edinburgh Inventory. Neuropsychologia, 9, 97-113.

Pfurtscheller, G., Brunner, C., Schlögl, A., \& Lopes da Silva, F. H. (2006). Mu rhythm (de)synchronization and EEG single-trial classification of different motor imagery tasks. NeuroImage, 31, 153-159.

Pfurtscheller, G., \& Lopes da Silva, F. H. (1999). Event-related EEG/MEG synchronization and desynchronization: Basic principles. Clinical Neurophysiology, 110, 1842-1857.

Pfurtscheller, G., \& Neuper, C. (1997). Motor imagery activates primary sensorimotor area in humans. Neuroscience Letters, 239, 65-68.

Pfurtscheller, G., Stancák, A., Jr., \& Neuper, C. (1996). Post-movement beta synchronization. A correlate of an idling motor area? Electroencephalography and Clinical Neurophysiology, 98, 281-293.

Pulvermüller, F., Härle, M., \& Hummel, F. (2001). Walking or talking?: Behavioral and neurophysiological correlates of action verb processing. Brain and Language, 78, 143-168. http://dx.doi.org/10.1006/brln.2000.2390.

Pulvermüller, F., Lutzenberger, W., \& Preissl, H. (1999). Nouns and verbs in the intact brain: Evidence from event-related potentials and high-frequency cortical responses. Cerebral Cortex, 9, 497-506.

Pulvermüller, F., Mohr, B., \& Schleichert, H. (1999). Semantic or lexico-syntactic factors: What determines word-class specific activity in the human brain? Neuroscience Letters, 275, 81-84.

Pulvermüller, F., Shtyrov, Y., \& Hauk, O. (2009). Understanding in an instant: Neurophysiological evidence for mechanistic language circuits in the brain Brain and Language, 110(2), 81-94. http://dx.doi.org/10.1016/j. bandl.2008.12.001.

Pulvermüller, F., Shtyrov, Y., \& Ilmoniemi, R. (2005). Brain signatures of meaning access in action word recognition. Journal of Cognitive Neuroscience, 17, 884-892.
Quandt, L. C., \& Marshall, P. J. (2014). The effect of action experience on sensorimotor EEG rhythms during action observation. Neuropsychologia, 56, 401-408. http://dx.doi.org/10.1016/j.neuropsychologia.2014.02.015.

Ritter, P., Moosmann, M., \& Villringer, A. (2009). Rolandic alpha and beta EEG rhythms' strengths are inversely related to fMRI-BOLD signal in primary somatosensory and motor cortex. Human Brain Mapping, 30, 1168-1187. http:// dx.doi.org/10.1002/hbm.20585.

Romero Lauro, L. J., Mattavelli, G., Papagno, C., \& Tettamanti, M. (2013). She runs, the road runs, my mind runs, bad blood runs between us: Literal and figurative motion verbs: An fMRI study. Neurolmage, 83, 361-371. http://dx.doi.org/ 10.1016/j.neuroimage.2013.06.050.

Sakreida, K., Scorolli, C., Menz, M. M., Heim, S., Borghi, A. M., \& Binkofski, F. (2013). Are abstract action words embodied? An fMRI investigation at the interface between language and motor cognition. Frontiers in Human Neuroscience, 7 , $1-13$.

Schaller, F., Weiss, S., \& Müller, H. M. (2016). "Pushing the button while pushing the argument": Motor priming of abstract action language. Cognitive Science (in press). http://dx.doi.org/10.1111/cogs.12433.

Schriefers, H., Friederici, A. D., \& Kühn, K. (1995). The processing of locally ambiguous relative clauses in German. Journal of Memory and Language, 34, 499-520.

Scorolli, C., Binkofski, F., Buccino, G., Nicoletti, R., Riggio, L., \& Borghi, A. M. (2011). Abstract and concrete sentences, embodiment, and languages. Frontiers in Psychology, 2, 1-11. http://dx.doi.org/10.3389/fpsyg.2011.00227.

Scorolli, C., Jacquet, P. O., Binkofski, F., Nicoletti, R., Tessari, A., \& Borghi, A. M. (2012). Abstract and concrete phrases processing differentially modulates cortico-spinal excitability. Brain Research, 1488, 60-71. http://dx.doi.org/ 10.1016/j.brainres.2012.10.004.

Simon, S., \& Mukamel, R. (2016). Power modulation of electroencephalogram mu and beta frequency depends on perceived level of observed actions. Brain and Behavior, 6, e00494. http://dx.doi.org/10.1002/brb3.494.

Tomasino, B., Fink, G. R., Sparing, R., Dafotakis, M., \& Weiss, P. H. (2008). Action verbs and the primary motor cortex: A comparative TMS study of silent reading, frequency judgments, and motor imagery. Neuropsychologia, 46, 1915-1926. http://dx.doi.org/10.1016/j.neuropsychologia.2008.01.015.

Troyer, M., Curley, L. B., Miller, L. E., Saygin, A. P. \& Bergen, B. K. (2014). Action verbs are processed differently in metaphorical and literal sentences depending on the semantic match of visual primes. Frontiers in Human Neuroscience, 8, 1-16. http://dx.doi.org/10.3389/fnhum.2014.00982.

van Elk, M., van Schie, H. T. Zwaan, R. A. \& Bekkering H. (2010). The functional role of motor activation in language processing: Motor cortical oscillations support lexical-semantic retrieval. Neurolmage, 50, 665-677. http://dx.doi.org/10.1016/ j.neuroimage.2009.12.123.

von Stein, A., Rappelsberger, P., Sarnthein, J., \& Petsche, H. (1999). Synchronization between temporal and parietal cortex during multimodal object processing in man. Cerebral Cortex, 9, 137-150.

Weiss, S., \& Müller, H. M. (2003). The contribution of EEG coherence to the investigation of language. Brain and Language, 85, 325-343. http://dx.doi.org/ 10.1016/S0093-934X(03)00067-1.

Weiss, S., \& Müller, H. M. (2012a). "Too many betas do not spoil the broth": The role of beta brain oscillations in language processing. Frontiers in Psychology, 3, 1-15. http://dx.doi.org/10.3389/fpsyg.2012.00201.

Weiss, S., \& Müller, H. M. (2012b). Processing arm-related verbs of motion: Behavioral and neurophysiological correlates. In Presented at the 4th UK cognitive linguistics conference, London.

Weiss, S., \& Müller, H. M. (2013). The non-stop road from concrete to abstract: High concreteness causes the activation of long-range networks. Frontiers in Human Neuroscience, 7, 1-13. http://dx.doi.org/10.3389/fnhum.2013.00526.

Weiss, S., Müller, H. M., Schack, B., King, J., Kutas, M., \& Rappelsberger, P. (2005). Increased neuronal communication accompanying sentence comprehension. International Journal of Psychophysiology, 57, 129-141. http://dx.doi.org/ 10.1016/j.ijpsycho.2005.03.013.

Weiss, S., \& Rappelsberger, P. (1996). EEG coherence within the 13-18 Hz band as a correlate of a distinct lexical organisation of concrete and abstract nouns in humans. Neuroscience Letters, 209, 17-20. http://dx.doi.org/10.1016/0304-3940 (96)12581-7.

Weiss, S., \& Rappelsberger, P. (1998). Left frontal EEG coherence reflects modality independent language processes. Brain Topography, 11, 33-42.

Weiss, S., \& Rappelsberger, P. (2000). Long-range EEG synchronization during word encoding correlates with successful memory performance. Brain Research, 9, 299-312.

Wilson, N. L., \& Gibbs, R. W. Jr., (2007). Real and imagined body movement primes metaphor comprehension. Cognitive Science, 31, 721-731.

Wingfield, A., Peelle, J. E., \& Grossman, M. (2003). Speech rate and syntactic complexity as multiplicative factors in speech comprehension by young and older adults. Aging Neuropsychology and Cognition, 10, 310-322. 